\title{
HIV Drug Resistance Profiles and Clinical Outcomes in Patients with Viremia Maintained at Very Low Levels
}

\author{
Michael R. Jordan ${ }^{1}$, Julie Winsett ${ }^{2}$, Aileen Tiro ${ }^{3}$, Vuth Bau ${ }^{1}$, Rony S. Berbara ${ }^{4}$, Christopher Rowley ${ }^{5}$, \\ Nobel Bellosillo $^{5}$, Christine Wanke ${ }^{1}$, Eoin P. Coakley ${ }^{6}$ \\ ${ }^{1}$ Tufts University School of Medicine, Boston, USA; ${ }^{2}$ Newton Wellesley Hospital, Newton, USA; ${ }^{3}$ Largo Medical Center, Clearwater, \\ USA; ${ }^{4}$ University of Massachusetts School of Medicine, Worcester, USA; ${ }^{5}$ Beth Israel Deaconess Medical Center, Boston, USA; \\ ${ }^{6}$ Monogram Biosciences, South San Francisco, USA. \\ Email: mjordan@tuftsmedicalcenter.org
}

Received January $5^{\text {th }}, 2013$; revised February $6^{\text {th }}, 2013$; accepted February $14^{\text {th }}, 2013$

Copyright (C) 2013 Michael R. Jordan et al. This is an open access article distributed under the Creative Commons Attribution License, which permits unrestricted use, distribution, and reproduction in any medium, provided the original work is properly cited.

\begin{abstract}
We describe an observational study of clinical, virologic and drug resistance profiles in HIV-positive antiretroviral adherent subjects with stable low level viremia (LLV) $50-1000$ copies/mL for more than 12 months. Subjects were followed from time of first detectable viral load (VL). In total, 102 episodes of LLV were detected among 80 individuals. The median (mean, range) HIV copy number at genotyping was $250(486,<50-3900)$ copies/mL after $14(17.9,0-58)$ months of LLV. Few patients maintained LLV for the entire 9 years period of observation, with half (52\%) experiencing viremic progression following a stable period of LLV either spontaneously or after treatment interruption or failed regimen intensification. In the setting of prolonged periods of sustained LLV, mean duration 22 (range 8 - 106) months, drug resistance (DR) was almost universal. Resistance to $\geq 1$ on-treatment drugs was defined in $97 \%$ of specimens and DR to all drugs in the treatment regimen in over half of all patients. Evolution of DR mutations during the period of LLV was observed in 20/28 (71\%) subjects with specimens available for follow-up testing. This evolution was associated with viremic progression to levels $>1000$ copies $/ \mathrm{mL}(\mathrm{p}=0.03)$. Our data suggest that DR present in patients with LLV is likely to impact long term clinical outcomes, highlighting the importance of optimizing techniques to detect the presence of drug resistant HIV in the setting of LLV and the need for larger prospective studies to assess the emergence of DR in the setting of sustained LLV and the impact of this DR on treatment outcomes.
\end{abstract}

Keywords: HIV; Low Level Viremia; Treatment Experienced Patients; HIV Drug Resistance

\section{Introduction}

Combination antiretroviral therapy (ART) has lead to dramatic reductions in HIV-associated morbidity and mortality [1-3]. Treatment goals for patients receiving ART include sustained undetectable viremia, [4-6] which is associated with favorable long-term clinical and immunological outcomes $[7,8]$. Undetectable viral load $(\mathrm{VL})$ is generally defined as HIV RNA $<50$ copies/mL (or $<40$ 75 copies/mL depending on the assay used) [6].

A subset of individuals taking ART will have persistent low level viremia (LLV), defined as a detectable VL between $50-1000$ copies $/ \mathrm{mL}$ over a sustained period of time [9]. Standard drug resistance (DR) testing may be unreliable and difficult to obtain when plasma viral loads range from 50 - 1000 copies $/ \mathrm{mL}$ [10]. Additionally, uncertainties remain regarding the significance of persistent low level viremia (LLV), including its contribution to the selection of DR, the impact of DR selected during LLV on sustained LLV, and the contribution of both to longterm clinical outcomes $[11,12]$. While detection of viremia suggests replicating virus, the VL threshold above which DR is selected remains uncertain $[13,14]$ and studies demonstrate variable rates of DR selection at levels of viremia below 1000 copies $/ \mathrm{ml}[15,16]$.

Some DR will inevitably emerge among individuals receiving suppressive treatment [17] and genotypic testing has been shown to be beneficial in guiding appropriate ART selection [18]. Given the goal of achieving an undetectable VL in patients receiving ART, clinicians may feel compelled to change therapy in the setting of LLV [19]. However, at low VL, genotypic information is often unavailable to guide regimen selection. This lack of genotypic data may lead to empiric treatment intensification (the addition of 1 or more antiretroviral drugs with 
undefined activity) or treatment interruption with the goal of obtaining a genotype after the VL rises $>1000$ copies $/ \mathrm{mL}$ ) [20]. Both clinical approaches are associated with risk. With empiric intensification, a suboptimal agent(s) may be added, which may promote multi-class DR [21]. With treatment interruption, rebound viremia, including potential high-level viremia, may result in systemic symptoms, CD4 cell count decline, and an increase in nonHIV related complications and pro-inflammatory changes [22,23].

While the literature suggests that patients experiencing intermittent LLV or "blips", seem to have little risk in terms of clinical progression or selection of DR [24,25], risks are less clear in the setting of sustained LLV [7, $9,16,26]$. Some studies describe progression to higher levels of viremia accompanied by the accumulation of high levels of DR [27], while others demonstrate limited selection of DR in patients with prolonged LLV and stable or increasing CD4 cell counts [28]. The largest studies show association between immune activation and control of LLV, despite accumulation of DR mutations, suggesting that the diminished viral fitness of emergent drug resistant strains facilitates long, stable periods of LLV [29-32].

The Beth Israel Deaconess Ultrasensitive Sequencing Information (BIDUSI) Study was a prospective observational cohort designed to characterize the natural history of LLV and the impact of detected DR on long-term clinical and virological outcomes.

\section{Methods}

\subsection{Study Design}

Patients were enrolled into the BIDUSI cohort from the outpatient Infectious Disease clinics at the Beth Israel Deaconess Medical Center, Boston, USA (BIDMC) or at Tufts Medical Center, Boston, USA (TMC). Eligible patients were enrolled from 1999-2005; long-term outcome data were abstracted through 2008, when available. Patients were eligible to participate if they had been taking an ART regimen (unchanged during the 6 months prior to enrollment) and had sustained LLV, defined as two or more consecutive VL measures of between 50 1000 copies $/ \mathrm{mL}$. Study inclusion criteria did not specify a minimum duration of LLV at study entry; however, only patients with LLV for 12 or more months were included in the analysis.

Eligibility criteria were regularly reviewed with outpatient clinicians who identified potentially eligible subjects. VL testing was performed as per standard of care. Subjects' medical records were reviewed after enrollment and during follow-up; patient age, gender, ethnicity, past medical history, anti-HIV treatments and relevant clinical events were abstracted. At study entry, the clini- cian and subject were interviewed and the medical record was reviewed for documentation of nonadherence relevant to period(s) of low level viremia. Subjects judged to be nonadherent were not considered eligible for this analysis. There was no formal adherence assessment during the study nor were there study specific follow-up visits. Rather clinicians were requested to have extra blood drawn for genotyping during routine clinic visits at times when VL was being measured. Ultimately follow-up blood specimens were obtained from only 20/80 $(25 \%)$ subjects largely because follow-up specimen acquisition was opportunistic.

DR genotyping was performed on plasma specimens obtained at study entry and at follow-up visits. For subjects with episodes of LLV separated by periods of VL $>1000$ copies $/ \mathrm{mL}$ or $<50$ copies $/ \mathrm{mL}$, subsequent episodes of LLV were included in the analysis if they were at least 6 months in duration. The study was approved by the Institutional Review Board at both BIDMC and TMC; all subjects provided written informed consent. To illustrate the maximal duration of LLV, HIV RNA values are summarized as the last available value between $50-1000$ copies $/ \mathrm{mL}$, i.e., prior to the endpoint of the LLV such as treatment interruption or intensification.

\subsection{Study Definitions and Outcomes}

For the purpose of this analysis, sustained LLV was defined as a VL between 50 - 1000 copies/mL for 12 months or longer. To allow for laboratory and physiologic variation, we accepted a single VL outlier, $<50$ copies $/ \mathrm{mL}$ or $>1000$ copies $/ \mathrm{mL}$, if the remainder were within range. The primary study endpoint was end of LLV defined as a $\mathrm{VL}>1000$ copies $/ \mathrm{mL}$ on one or more consecutive tests.

ART regimens were classified by drug class: Nucleotide reverse transcriptase inhibitor (NRTI) only, unboosted protease inhibitor (PI) in combination with an NRTI, boosted PI (PI in combination with ritonavir) and an NRTI, or a non-nucleoside reverse transcriptase inhibitor (NNRTI) and an NRTI, or other (dual PI, NRTI/dual PI, and NRTI/ NNRTI/PI).

\subsection{HIV RNA Quantitation}

VL measurements were performed using the Versant bDNA assay (Roche Diagnostic Systems, Branchburg, NJ, USA).

\subsection{HIV Drug Resistance Genotyping}

HIV RNA was harvested using a standard guanidinium isothiocyanate alcohol extraction method [33] and population based sequencing was performed using a previously described protocol and primer sets optimized to amplify HIV-1 subtype B at low levels of viremia [34, 35]. A $1.3 \mathrm{~kb}$ fragment of gag-pol (p6-RT region) was 
amplified by 35-cycle RT-PCR using MuLV reverse transcriptase (Perkin Elmer, Waltham, MA, USA) and a subsequent 25-cycle nested PCR using rTth XLtaq polymerase (Perkin Elmer Waltham, MA, USA). Standard dideoxy sequencing was performed using conserved primers (Macrogen, Seoul, South Korea). All nucleotide sequences were aligned using Clustal X [36]. Alignments were visually inspected and frame shifts were removed using BioEdit sequence editor version 7.0 [37]. Sequences were complied and a single Neighbor Joining tree with 1000 bootstrap replicates was constructed using Mega 3.0 [38] to assess for sequence overlap (data not shown). Genotyping susceptibility scores were assigned [39].

\subsection{HIV Phenotyping}

A set of LLV plasma specimens from 17 individuals was characterized by a single cycle recombinant virus phenotyping assay (PhenoSense, Monogram Biosciences, South San Francisco CA).

\subsection{Statistical Methods}

To describe the overall study population, median (mean, range) for continuous variables and proportions for categorical variables were calculated. Statistical analyses were performed using SPSS (Version 15, Chicago, IL, USA).

\section{Results}

\subsection{Demographics, Regimens and Genotypic Susceptibility Score}

A total of 80 individuals were enrolled with a median age of 43 (range 23 - 84) years. 18\% were female. Of these 75 (95\%) were Caucasian, two were African American and 3 were Hispanic. Among these 80 individuals there were 102 episodes of LLV (Table 1).

At study enrollment, all subjects were receiving antiHIV therapy. At enrolment median HIV RNA was 278 copies $/ \mathrm{mL}$ and median CD4 count was 420 cells $/ \mathrm{mm}^{3}$. The antiretrovirals used reflected prescribing patterns over the time of sampling with $66 \%$ of specimens obtained in 2001 or earlier. NRTIs were used in 79/80 (99\%) individuals with lamivudine (3TC), stavudine (d4T), zidovudine (ZDV), abacavir (ABC) and didanosine (ddI) being used $82 \%, 65 \%, 15 \%, 23 \%$ and $15 \%$ of the time, respectively. The most common NRTI combination was d4T-3TC, 53\%. NNRTIs were used in 33\%; nevirapine (NVP), $14 \%$ and efavirenz (EFV) $15 \%$. PIs were used in $54 \%$, nelfinavir (NFV), 19\%, amprenavir (APV/r), 14\%, lopinavir/ritonavir (LPV/r), 9\%, indinavir/ritonavir (IDV/r), $10 \%$. Combinations of PIs were used in only $9 \%$, e.g., $\mathrm{LPV} / \mathrm{r}$ with $\mathrm{APV}(5 \%)$, this combination was used as exclusive therapy in the only individual not receiving NRTI therapy.

132 drug resistance genotypes were generated from 80 individuals experiencing $102 \mathrm{LLV}$ episodes. The median (mean, range) HIV RNA at genotyping was 250 (486, $<50$ - 3900) copies $/ \mathrm{mL}$ after 14 (17.9, 0 - 58) months LLV. The proportions genotyped with HIV RNA levels $<500$ copies $/ \mathrm{mL},<200$ copies $/ \mathrm{mL}$ and $<50$ copies $/ \mathrm{mL}$ were $69 \%, 39 \%$ and $3 \%$, respectively. The proportions genotyped after $\geq 12$ or $\geq 24$ months of LLV were $64 \%$ and $30 \%$, respectively. The median (mean, range) number of drugs used in each regimen was 3 (3.1, 2 - 6). By contrast the median (mean, range) genotyping susceptibility score (GSS) was only $1(1.1,0-4)$ with $67 \%$ of individuals having a GSS $\leq 1$. Therefore $2 / 3$ of subjects demonstrated genotypic resistance to all drugs in the treatment regimen and only $6 / 80(7.5 \%)$ had no DR mutations. Thus, resistance to therapy was the hallmark of this cohort.

\subsection{HIV Phenotyping}

A set of LLV plasma specimens from 17 individuals was characterized by a single cycle recombinant virus phenotyping assay (PhenoSense, Monogram Biosciences, South San Francisco CA) for the purposes of providing a resistance profiling by an alternative technology. In all cases the LLV genotype and phenotype results were highly concordant, providing further support for the broader resistance observations in the cohort (data not shown).

Table 1. Summary of HIV RNA and CD4 cell count values over period of low level viremia.

\begin{tabular}{|c|c|}
\hline Outcome & Total \\
\hline Number of episodes & 102 \\
\hline Duration of LLV (months) & $\begin{array}{c}22 \\
(8-106)\end{array}$ \\
\hline Initial HIV RNA (copies/mL) & $\begin{array}{c}275 \\
(53-999)\end{array}$ \\
\hline Last HIV RNA (copies/mL) & $\begin{array}{c}264 \\
(50-999)\end{array}$ \\
\hline Change in HIV RNA (copies/mL) & $\begin{array}{c}-1 \\
(-898-+931)\end{array}$ \\
\hline Initial CD4 cell count (cells $\left./ \mathrm{mm}^{3}\right)$ & $\begin{array}{c}514 \\
(73-1155)\end{array}$ \\
\hline Last CD4 cell count (cells $/ \mathrm{mm}^{3}$ ) & $\begin{array}{c}538 \\
(77-1351)\end{array}$ \\
\hline Change in CD4 cell count (cells $/ \mathrm{mm}^{3}$ ) & $\begin{array}{c}+41 \\
(-502-+433)\end{array}$ \\
\hline
\end{tabular}

$\mathrm{LLV}=$ low level viremia; data presented are median and range. 


\subsection{HIV Drug Resistance in Relation to Specific Antiretroviral Therapy}

Among 3TC, EFV/NVP and NFV recipients the signature mutations $\mathrm{M} 184 \mathrm{~V}, \mathrm{~K} 103 \mathrm{~N} / \mathrm{Y} 181 \mathrm{C}$ and $\mathrm{D} 30 \mathrm{~N}$ were seen in $89 \%, 63 \%$ and $53 \%$, respectively. Among 53/80 (66\%) d4T recipients the median d4T GSS was 0.5 with $21 \%$ being fully $\mathrm{d} 4 \mathrm{~T}$ resistant and $33 \%$ being fully susceptible. NFV was the most commonly used PI with 13/15 (87\%) being NFV resistant; 11/13 (85\%) with either D30N or L90M.

\subsection{Emergence of Drug Resistance}

28 individuals had a median $2(3,2-7)$ genotypes performed during the study period. The first and last genotypes were performed at median HIV RNA of 296 (494, $67-1.283)$ copies $/ \mathrm{mL}$ and $345(452,58-1.288)$ copies/mL, respectively, with a median change of $-46(+1096$, $-42-1028$,) copies $/ \mathrm{mL}$. The interval between first and last genotype was $15(15.3,2$ - 38) months of LLV.

To track changes in the number of DR mutations a simple scoring system was used; $+/-1$ or $+/-0.5$ (mutation or mutation mixed with wild type at that amino acid position). The median (mean, range) number of mutations at first genotype was $6(6.5,0-18)$. Evolution of DR during periods of LLV was observed in 20/28 (71\%) subjects. Among these 20 subjects, 13 acquired mutations, 2 lost mutations and 5 both gained and lost mutations. The changes captured on follow-up genotypes are described in Table 2. Most but not all are directional, i.e. readily related to drug exposure or drug removal.

A comparison of the characteristics of specimens with and without mutation changes was made (Table 3). In general, those with genotypic change had more mutations at first genotype, higher VLs at both time points and longer time periods between genotypes. Viremic progressors also had greater changes in HIV RNA at last genotype, although this difference was not significant. While none of the 8 patients with no genotypic evolution experienced viremic progression, 8/20 (40\%) patients with mutation changes (gain or loss) subsequently experienced viremic progression; $p=0.03$.

During the period of observation, a total of 40 patients had treatment intensification with the addition of $\leq 1$ ( $\mathrm{n}=$ 16) or $\geq 2$ agents $(n=24)$, retrospectively, judged to be fully active based on LLV resistance testing. Treatment intensification was successful in 18/24 (75\%) and 5/16 (31\%) with $\geq 2$ or $\leq 1$ fully active agents added to the regimen, respectively, $\mathrm{p}<0.05$.

\section{Discussion}

In this analysis of an HIV infected treatment experienced population on ART, we observed that during periods of sustained LLV VL remained stable and CD4 cell counts either remained stable or increased. However, few patients maintained LLV for the entire 9 years period of observation, with half (52\%) experiencing viremic progression following a stable period of LLV either spontaneously or after treatment interruption or regimen intensification. Although prolonged periods of sustained LLV were documented, 22 (range 8 - 106) months, DR was extremely common, with DR to $\geq 1$ on treatment drugs observed in almost all specimens tested (97\%) and resistance to all drugs in the prescribed treatment regimen observed in over half of all patients.

Notably $40 \%$ of all treatment intensifications were unsuccessful in achieving viral suppression suggesting that changes in regimen may lead to viremic progression and although VLs were $<1000$ copies/mL, existing DR or DR selected for by the addition of inactive drugs may have contributed to subsequent virologic failure. Treatment intensification with two or more fully active agents resulted in viral suppression in $78 \%$ of subjects.

Not surprisingly, treatment interruption was associated with marked CD4 cell loss and viral rebound to levels above 1000 copies $/ \mathrm{mL}$. This observation suggests that in the setting of sustained LLV, ARVs are likely to maintain significant activity permitting stable CD4 cell counts, even in the presence of DR [40]. It is likely that the virus in patients with prolonged episodes of LLV had decreased replication capacity compared to virus from those with shorter or no episodes of LLV; however, replication capacity data were unavailable for this analysis. Although data were insufficient to evaluate for clinical events related to treatment interruption, the observed rise in VL and decrease in CD4 cell count suggests disease progression and potential adverse clinical outcomes.

Overall, we demonstrated substantial DR, with most patients demonstrating mutations to one or more ontreatment drugs. Patients with genotypic evolution had more mutations at first genotype, higher VLs at both time points and longer time periods between genotypes. Overall, lack of genotypic evolution was not associated with viremic progression. However, in this cohort the majority of patients gained DR mutations during periods of LLV, which may further limit future effective treatment options.

Limitations to our study include its small sample size, retrospective data abstraction and lack of standardized measures of patient adherence to prescribed ART. Additionally, DR genotyping was performed using population based sequencing techniques; thus, it is possible that DR mutations present as minor variants in the viral population were not amplified [41]; however, the clinical relevance of these low frequency mutations remains uncertain and therefore does not lessen the importance of our observations [42]. Additionally, genotypic data do not allow for the assessment of viral function and it is possible 
Table 2. Subjects with changes in HIV drug resistance mutations over median of 15 months of follow-up $(\mathbf{n}=\mathbf{2 0})$.

\begin{tabular}{|c|c|c|c|c|c|}
\hline & Treatment & Baseline RT & Baseline PR & Gain & Loss \\
\hline 1 & $\mathrm{~d} 4 \mathrm{~T}, 3 \mathrm{TC}, \mathrm{ABC}$ & $\begin{array}{l}\text { D67N, T69D, K70R, K103N, } \\
\text { M184V, K219Q, K238K/T }\end{array}$ & I85I/V, L90L/M & RT: M41/L, T215F & $\begin{array}{l}\text { Protease: I85I/V, } \\
\text { L90L/M }\end{array}$ \\
\hline 2 & $\mathrm{~d} 4 \mathrm{~T}, 3 \mathrm{TC}, \mathrm{NVP}$ & $\begin{array}{l}\text { M41L, V118I, Y181C, } \\
\text { L210W, T215Y }\end{array}$ & A71V & RT: K103N & - \\
\hline 3 & $\mathrm{ABC}, \mathrm{d} 4 \mathrm{~T}, \mathrm{ddI}, 3 \mathrm{TC}$ & $\mathrm{T} 215 \mathrm{~L}$ & WT & $\begin{array}{l}\text { RT: M41L, M184V, } \\
\text { L210W, T215F }\end{array}$ & - \\
\hline 4 & $\mathrm{ABC}, \mathrm{d} 4 \mathrm{~T}, 3 \mathrm{TC}$ & D67N, K70R, M184V, K219Q & WT & RT: 98G & - \\
\hline 5 & $\mathrm{~d} 4 \mathrm{~T}, 3 \mathrm{TC}, \mathrm{IDV}$ & $\begin{array}{l}\text { M41L, E44D, D67N, T69D, } \\
\text { M184M/V, L210W, T215Y }\end{array}$ & $\begin{array}{l}\text { L10I, G73A, I84V, } \\
\text { I85V, L90M }\end{array}$ & RT: M184V & - \\
\hline 6 & $\mathrm{~d} 4 \mathrm{~T}, 3 \mathrm{TC}, \mathrm{NVP}$ & K103N, Y181F/Y,M184V & WT & - & RT: $181 \mathrm{~F} / \mathrm{Y}$ \\
\hline 7 & $\begin{array}{l}\mathrm{d} 4 \mathrm{~T}, 3 \mathrm{TC}(\mathrm{ABC} \text { and } \mathrm{APV} / \mathrm{r} \\
\text { added , EFV discontinued) }\end{array}$ & M41L, M184V, T210W, T215Y & WT & - & RT: L210W \\
\hline 8 & $\mathrm{~d} 4 \mathrm{~T}, 3 \mathrm{TC}, \mathrm{EFV}$ & $\begin{array}{l}\text { M41L, E44D/E, K103N, V118I, } \\
\text { M184V, T215Y, K219R, K238T }\end{array}$ & $\begin{array}{l}\text { L63C, I72V, V77I, } \\
\text { L90M, I93L }\end{array}$ & RT: D67N, R219S & - \\
\hline 9 & $\mathrm{~d} 4 \mathrm{~T}, 3 \mathrm{TC}, \mathrm{NFV}$ & $\begin{array}{l}\text { D67N, T69N, K70R, } \\
\text { M184V, K219Q }\end{array}$ & $\begin{array}{l}\mathrm{D} 30 \mathrm{~N}, \mathrm{~L} 33 \mathrm{~F} / \mathrm{L} \\
\mathrm{M} 46 \mathrm{I} / \mathrm{M}, \mathrm{N} 83 \mathrm{H}, \mathrm{N} 88 \mathrm{D}\end{array}$ & Protease: Q58E/Q & $\begin{array}{l}\text { Protease: } 33 \mathrm{~F}, 36 \mathrm{~L} \text {, } \\
\quad 46 \mathrm{I}, 58 \mathrm{Q}, 83 \mathrm{H}\end{array}$ \\
\hline 10 & $\mathrm{~d} 4 \mathrm{~T}, 3 \mathrm{TC}, \mathrm{ABC}, \mathrm{NVP}$ & $\begin{array}{l}\text { D67N, T69N, K70R, M184V, } \\
\text { Y188L, T215F, K219Q }\end{array}$ & L10I & RT: M41L & - \\
\hline 11 & $\begin{array}{l}\text { d4T, 3TC, (EFV added, } \\
\text { NFV discontinued) }\end{array}$ & $\mathrm{M} 184 \mathrm{~V}, 138 \mathrm{~A}$ & $\begin{array}{l}\text { L10I, D30N, } \\
\text { A71V, N88D }\end{array}$ & RT: $103 \mathrm{~N}, 108 \mathrm{I} / \mathrm{V}$ & RT: $138 \mathrm{~A}$ \\
\hline 12 & ZDV, 3TC (EFV added) & K70R, M184V & WT & $\begin{array}{l}\text { RT: } 103 \mathrm{~N}, 219 \mathrm{Q} \\
225 \mathrm{H}, 238 \mathrm{~T}\end{array}$ & - \\
\hline 13 & $\begin{array}{l}\mathrm{d} 4 \mathrm{~T}, 3 \mathrm{TC}, \mathrm{ABC} \\
\mathrm{NVP}, \mathrm{IDV} / \mathrm{r}\end{array}$ & $\begin{array}{l}\text { M41L, E44D, D67N, A98G, } \\
\text { V106I, V118I, Y181C, M184V, } \\
\text { L210W, T215Y, K219D }\end{array}$ & $\begin{array}{l}\text { L10I, L33F, F53L, } \\
\text { I54V, A71V, V82F, L90M }\end{array}$ & $\begin{array}{c}\text { RT: 208Y, } \\
211 \mathrm{~K}, \mathrm{D} 219 \mathrm{~N}\end{array}$ & - \\
\hline 14 & $\begin{array}{l}\text { ZDV, ddI, 3TC, } \\
\text { ABC, LPV/r, APV }\end{array}$ & L210W, T215Y & WT & Protease: $33 \mathrm{~F}, 43 \mathrm{~T}$ & RT: V108I \\
\hline 15 & $\begin{array}{l}\mathrm{d} 4 \mathrm{~T}, \mathrm{ddI}, \mathrm{APV} \\
\text { hydroxyurea }\end{array}$ & $\begin{array}{l}\text { M41L, L74I, K103N, V108IV, } \\
\text { V118I, M184V, L210W, } \\
\text { T215Y, K219K/R }\end{array}$ & $\begin{array}{l}\text { L10I, M46L, G48V, } \\
\text { I54V, V82A, I84IV }\end{array}$ & $\begin{array}{l}\text { Protease: } 33 \mathrm{~F}, \\
\text { T82A }\end{array}$ & \\
\hline 16 & $\mathrm{~d} 4 \mathrm{~T}, 3 \mathrm{TC}, \mathrm{ABC}$ & $\begin{array}{l}\text { M41L, D67N, T69N, K70R, } \\
\text { K103N, M184V, T215F, K219Q }\end{array}$ & L10I & RT 98G & RT: T69N \\
\hline 17 & $\begin{array}{l}\text { d4T, 3TC, EFV } \\
\text { (ABC added) }\end{array}$ & $\begin{array}{l}\text { D67N, K70R, K103N, } \\
\text { M184V, K219H }\end{array}$ & WT & RT: Y181Y/C & \\
\hline 18 & LPV/r, APV & WT & WT & $\begin{array}{l}\text { Protease: 10I/R, } \\
\text { 36I/M, 46M/L, 63P }\end{array}$ & \\
\hline 19 & d4T, ddI, 3TC & K70R, M184V & WT & Protease: I85I/V & \\
\hline 20 & ZDV, 3TC, APV/r & $\begin{array}{l}\text { D67G, T69N, K70R, } \\
\text { K103N, M184V, L210F }\end{array}$ & $\mathrm{I} 54 \mathrm{~L} / \mathrm{V}, \mathrm{V} 82 \mathrm{~F}$ & RT: 219Q & \\
\hline
\end{tabular}

$\mathrm{RT}=$ reverse transcriptase; $\mathrm{d} 4 \mathrm{~T}=$ stavudine; $3 \mathrm{TC}=$ lamivudine; $\mathrm{ABC}=$ abacavir; $\mathrm{NVP}=$ nevirapine; ddI = didanosine; $\mathrm{EFV}=$ efavirenz; $\mathrm{NFV}=$ nelfinavir; $\mathrm{ZDV}=$ zidovudine; IDV = indinavir; LPV = lopinavir; APV = amprenavir; $r=$ ritonavir; WT = wild type. 
Table 3. Characteristics of specimens with and without mutation changes.

\begin{tabular}{lcc}
\hline & No change & Change \\
\hline Number of patients & $\mathrm{N}=8$ & $\mathrm{~N}=20$ \\
Number of genotypes over follow-up period (median) & 3.5 & 2 \\
Mutation differences from first to last genotype & 0 & +1.5 \\
Number of mutations detected at first genotype (median) & 3 & 7 \\
Time between first and last genotype & 133 copies $/ \mathrm{mL}$ & $412.5 \mathrm{cophths}$ \\
HIV RNA at first genotype $/ \mathrm{mL}$ \\
HIV RNA at last genotype (median) & 112 copies $/ \mathrm{mL}$ & $449 \mathrm{copies} / \mathrm{mL}$ \\
Change in HIV RNA first to last genotype & -68 copies $/ \mathrm{mL}$ & $+104 \mathrm{copies} / \mathrm{mL}$ \\
Proportion with viremic progression to levels $>1000$ copies $/ \mathrm{mL}$ & $0 / 8(0 \%)$ & $8 / 20(40 \%)$ \\
\hline
\end{tabular}

that the virus amplified from plasma specimens was not representative of actively replicating virus in lymph nodes. Furthermore, in many patients, LLV was artificially terminated, either as a result of treatment intensification or treatment interruption. Thus, the natural history of LLV in these patients cannot be fully assessed. Finally, $16 \%$ of subjects were lost to follow-up; although these patients showed LLV at time of last follow-up, the true duration of their LLV and subsequent virologic outcome remain unknown. Although the small sample size and descriptive nature of this study greatly limit generalizability of our findings, data suggest that DR present in patients with LLV is likely to impact long term clinical outcomes. Our results highlight the importance of optimizing techniques to detect the presence of drug resistant HIV in the setting of LLV and the need for larger prospective studies to assess the emergence of DR in the setting of sustained LLV and to prospectively assess their impact on treatment outcomes.

\section{Acknowledgements}

MRJ and JW were supported by the National Institute for Allergy and Infectious Disease: T32 AI07389; CFAAR 1P30A142853-10; K24 A1055293-06A1; and the Center for Drug Abuse and AIDS Research: P30 DA013868. MRJ was also supported by the National Institute for Allergy and Infectious Disease: K23 AI074423-05. The authors are most grateful to Heidi Sheehan, Tufts University, for her statistical support and review of the manuscript.

\section{REFERENCES}

[1] G. Panos, G. Samonis, V. G. Alexiou, G. A. Kavarnou, G. Charatsis and M. E. Falagas, "Mortality and Morbidity of
HIV Infected Patients Receiving HAART: A Cohort Study," Current HIV Research, Vol. 6, No. 3, 2008, pp. 257-260. doi: $10.2174 / 157016208784324976$

[2] R. P. Walensky, K. A. Freedberg, M. C. Weinstein and A. D. Paltiel, "Cost-Effectiveness of HIV Testing and Treatment in the United States," Clinical Infectious Diseases, Vol. 45, Suppl. 4, 2007, pp. S248-S254. doi: $10.1086 / 522546$

[3] World Health Organization, UNAIDS, UNICEF, “Towards Universal Access: Scaling up Priority HIV/AIDS Interventions in the Health Sector," 2010.

http://www.who.int/hiv/pub/2010progressreport/en/index. html

[4] J. A. Aberg, J. E. Gallant, J. Anderson, et al., "Primary Care Guidelines for the Management of Persons Infected with Human Immunodeficiency Virus: Recommendations of the HIV Medicine Association of the Infectious Diseases Society of America," Clinical Infectious Diseases, Vol. 39, No. 5, 2004, pp. 609-629. doi:10.1086/423390

[5] S. M. Hammer, J. J. Eron Jr., P. Reiss, et al., "Antiretroviral Treatment of Adult HIV Infection: 2008 Recommendations of the International AIDS Society-USA Panel," JAMA, Vol. 300, No. 5, 2008, pp. 555-570. doi:10.1001/jama.300.5.555

[6] Panel on Antiretroviral Guidelines for Adults and Adolescents, Department of Health and Human Services, "Guidelines for the Use of Antiretroviral Agents in HIV1-Infected Adults and Adolescents," 2011.

http://www.aidsinfo.nih.gov/ContentFiles/AdultandAdole scentGL.pdf

[7] A. M. Geretti, C. Smith, A. Haberl, et al., "Determinants of Virological Failure after Successful Viral Load Suppression in First-Line Highly Active Antiretroviral Therapy," Antiviral Therapy, Vol. 13, No. 7, 2008, pp. $927-$ 936.

[8] C. H. Olsen, J. Gatell, B. Ledergerber, et al., "Risk of AIDS and Death at Given HIV-RNA and CD4 Cell Count, in Relation to Specific Antiretroviral Drugs in the Regi- 
men," AIDS, Vol. 19, No. 3, 2005, pp. 319-330.

[9] C. Cohen, "Low-Level Viremia in HIV-1 Infection: Consequences and Implications for Switching to a New Regimen," HIV Clinical Trials, Vol. 10, No. 2, 2009, pp. 116-124. doi:10.1310/hct1002-116

[10] R. E. Nettles, T. L. Kieffer, R. P. Simmons, et al., "Genotypic Resistance in HIV-1-Infected Patients with Persistently Detectable Low-Level Viremia While Receiving Highly Active Antiretroviral Therapy," Clinical Infectious Diseases, Vol. 39, No. 7, 2004, pp. 1030-1037. doi:10.1086/423388

[11] N. H. Tobin, G. H. Learn, S. E. Holte, et al., "Evidence That Low-Level Viremias during Effective Highly Active Antiretroviral Therapy Result from Two Processes: Expression of Archival Virus and Replication of Virus," Journal of Virology, Vol. 79, No. 15, 2005, pp. 96259634. doi:10.1128/JVI.79.15.9625-9634.2005

[12] S. A. Van, S. Zhang, P. Reiss, et al., "Immunologic, Virologic, and Clinical Consequences of Episodes of Transient Viremia during Suppressive Combination Antiretroviral Therapy," Journal of Acquired Immune Deficiency Syndromes, Vol. 48, No. 1, 2008, pp. 104-108. doi:10.1097/QAI.0b013e31816a1d4f

[13] Y. Mitsuya, M. A. Winters, W. J. Fessel, et al., "HIV-1 Drug Resistance Genotype Results in Patients with Plasma Samples with HIV-1 RNA Levels Less than 75 Copies/mL," Journal of Acquired Immune Deficiency Syndromes, Vol. 43, No. 1, 2006, pp. 56-59. doi:10.1097/01.qai.0000232609.99705.a2

[14] T. Doyle and A. M. Geretti, "Low-Level Viraemia on HAART: Significance and Management," Current Opinion in Infectious Diseases, Vol. 25, No. 1, 2012, pp. 1725. doi:10.1097/QCO.0b013e32834ef5d9

[15] A. C. Karlsson, S. R. Younger, J. N. Martin, et al., "Immunologic and Virologic Evolution during Periods of Intermittent and Persistent Low-Level Viremia," AIDS, Vol. 18, No. 7, 2004, pp. 981-989. doi:10.1097/00002030-200404300-00005

[16] B. Taiwo, S. Gallien, E. Aga, H. Ribaudo, R. Haubrich, D. R. Kuritzkes and J. J. Eron Jr., "Antiretroviral Drug Resistance in HIV-1-Infected Patients Experiencing Persistent Low-Level Viremia during First-Line Therapy," Journal of Infectious Diseases, Vol. 204, No. 4, 2011, pp. 515-520. doi:10.1093/infdis/jir353

[17] M. Hermankova, S. C. Ray, C. Ruff, et al., "HIV-1 Drug Resistance Profiles in Children and Adults with Viral Load of $<50$ copies/ml Receiving Combination Therapy," JAMA, Vol. 286, No. 2, 2001, pp. 196-207. doi:10.1001/jama.286.2.196

[18] M. S. Hirsch, H. F. Gunthard, J. M. Schapiro, et al., "Antiretroviral Drug Resistance Testing in Adult HIV-1 Infection: 2008 Recommendations of an International AIDS Society-USA Panel," Clinical Infectious Diseases, Vol. 47, No. 2, 2008, pp. 266-285. doi:10.1086/589297

[19] R. E. Nettles, T. L. Kieffer, P. Kwon, et al., "Intermittent HIV-1 Viremia (Blips) and Drug Resistance in Patients Receiving HAART," JAMA, Vol. 293, No. 7, 2005, pp. 817-829. doi:10.1001/jama.293.7.817

[20] J. L. Sirvent, M. M. Socas, C. H. Calzadilla, A. M. Lirola and M. R. Valls, "Utility of Interrupting Antiretroviral Treatment before HIV Drug Resistance Testing in Patients with Persistently Detectable Low-Level Viremia," Journal of Acquired Immune Deficiency Syndromes, Vol. 40, No. 1, 2005, pp. 111-113. doi:10.1097/01.qai.0000174650.33159.22

[21] J. Ena, R. F. Ruiz de Apodaca, C. Amador, C. Benito and F. Pasquau, "Net Benefits of Resistance Testing Directed Therapy Compared with Standard of Care in HIV-Infected Patients with Virological Failure: A Meta-Analysis," Enfermedades Infecciosas y Microbiología Clínica, Vol. 24, No. 4, 2006, pp. 232-237. doi:10.1016/S0213-005X(06)73768-5

[22] J. V. Baker, G. Peng, J. Rapkin, et al., "CD4+ Count and Risk of Non-AIDS Diseases Following Initial Treatment for HIV Infection,” AIDS, Vol. 22, No. 7, 2008, pp. 841848. doi:10.1097/QAD.0b013e3282f7cb76

[23] J. Lawrence, D. L. Mayers, K. H. Hullsiek, et al., "Structured Treatment Interruption in Patients with MultidrugResistant Human Immunodeficiency Virus," New England Journal of Medicine, Vol. 349, No. 9, 2003, pp. 837846. doi:10.1056/NEJMoa035103

[24] P. K. Lee, T. L. Kieffer, R. F. Siliciano and R. E. Nettles, "HIV-1 Viral Load Blips Are of Limited Clinical Significance," Journal of Antimicrobial Chemotherapy, Vol. 57, No. 5, 2006, pp. 803-805. doi:10.1093/jac/dk1092

[25] D. V. Havlir, R. Bassett, D. Levitan, et al., "Prevalence and Predictive Value of Intermittent Viremia with Combination HIV Therapy," JAMA, Vol. 286, No. 2, 2001, pp. 171-179. doi:10.1001/jama.286.2.171

[26] R. Mohey, L. B. Jorgensen, B. K. Moller, F. T. Black, J. Kjems and N. Obel, "Detection and Quantification of Proviral HIV-1 $184 \mathrm{M} / \mathrm{V}$ in Circulating CD4(+) T Cells of Patients on HAART with a Viremia Less than 1,000 copies/ml," Journal of Clinical Virology, Vol. 34, No. 4, 2005, pp. 257-267. doi:10.1016/j.jcv.2005.02.015

[27] A. C. Karlsson, S. R. Younger, J. N. Martin, et al., "Immunologic and Virologic Evolution during Periods of Intermittent and Persistent Low-Level Viremia," AIDS, Vol. 18, No. 7, 2004, pp. 981-989. doi:10.1097/00002030-200404300-00005

[28] S. S. Kaplan, G. Ferrari, T. Wrin, et al., "Longitudinal Assessment of Immune Response and Viral Characteristics in HIV-Infected Patients with Prolonged CD4(+)/ Viral Load Discordance," AIDS Research and Human Retroviruses, Vol. 21, No. 1, 2005, pp. 13-16. doi:10.1089/aid.2005.21.13

[29] S. G. Deeks, J. N. Martin, E. Sinclair, et al., "Strong Cell-Mediated Immune Responses Are Associated with the Maintenance of Low-Level Viremia in AntiretroviralTreated Individuals with Drug-Resistant Human Immunodeficiency Virus Type 1," Journal of Infectious Diseases, Vol. 189, No. 2, 2004, pp. 312-321. doi: $10.1086 / 380098$

[30] S. G. Deeks, "Durable HIV Treatment Benefit Despite Low-Level Viremia: Reassessing Definitions of Success or Failure," JAMA, Vol. 286, No. 2, 2001, pp. 224-226. doi:10.1001/jama.286.2.224

[31] A. C. Karlsson, S. R. Younger, J. N. Martin, et al., "Im- 
munologic and Virologic Evolution during Periods of Intermittent and Persistent Low-Level Viremia," AIDS, Vol. 18 , No. 7, 2004, pp. 981-989. doi:10.1097/00002030-200404300-00005

[32] C. M. Vaamonde, D. R. Hoover, K. Anastos, et al., "Factors Associated with Poor Immunologic Response to Virologic Suppression by Highly Active Antiretroviral Therapy in HIV-Infected Women," AIDS Research and Human Retroviruses, Vol. 22, No. 3, 2006, pp. 222-231. doi:10.1089/aid.2006.22.222

[33] L. Q. Zhang, P. Simmonds, C. A. Ludlam and A. J. Brown, "Detection, Quantification and Sequencing of HIV-1 from the Plasma of Seropositive Individuals and from Factor VIII Concentrates," AIDS, Vol. 5, No. 6, 1991, pp. 675681. doi:10.1097/00002030-199106000-00006

[34] E. P. Coakley, et al., "HIV Drug Resistance Profiles and Clinical and Virologic Outcomes among HIV-infected Subjects with Stable Detectable Plasma Viral Loads < 1000 copies/mL for at Least 12 Months," CROI, 2002.

[35] M. R. Jordan, M. Kearney, S. Palmer, W. Shao, F. Maldarelli, E. P. Coakley, C. Chappey, C. Wanke and J. M. Coffin, "Comparison of Standard PCR/Cloning to Single Genome Sequencing for Analysis of HIV-1 Populations," Journal of Virological Methods, Vol. 168, No. 1-2, 2010, pp. 114-120. doi:10.1016/j.jviromet.2010.04.030

[36] R. Chenna, H. Sugawara, T. Koike, et al., "Multiple Sequence Alignment with the Clustal Series of Programs," Nucleic Acids Research, Vol. 31, No. 13, 2003, pp. 3497-
3500. doi: $10.1093 / \mathrm{nar} / \mathrm{gkg} 500$

[37] BioEdit, 2012.

http://www.mbio.ncsu.edu/bioedit/bioedit.html

[38] Mega 3.0, 2012. http://www.megasoftware.net

[39] T. F. Liu and R. W. Shafer, "Web Resources for HIV Type 1 Genotypic-Resistance Test Interpretation," Clinical Infectious Diseases, Vol. 42, No. 11, 2006, pp. 16081618. doi: $10.1086 / 503914$

[40] I. Kousignian, S. Abgrall, S. Grabar, et al., "Maintaining Antiretroviral Therapy Reduces the Risk of AIDS-Defining Events in Patients with Uncontrolled Viral Replication and Profound Immunodeficiency," Clinical Infectious Diseases, Vol. 46, No. 2, 2008, pp. 296-304. doi:10.1086/524753

[41] S. Palmer, M. Kearney, F. Maldarelli, et al., "Multiple, Linked Human Immunodeficiency Virus Type 1 Drug Resistance Mutations in Treatment-Experienced Patients Are Missed by Standard Genotype Analysis," Journal of Clinical Microbiology, Vol. 43, No. 1, 2005, pp. 406-413. doi:10.1128/JCM.43.1.406-413.2005

[42] Y. Mitsuya, M. A. Winters, W. J. Fessel, et al., "HIV-1 Drug Resistance Genotype Results in Patients with Plasma Samples with HIV-1 RNA Levels Less than 75 copies/mL," Journal of Acquired Immune Deficiency Syndromes, Vol. 43, No. 1, 2006, pp. 56-59. doi:10.1097/01.qai.0000232609.99705.a2 